\title{
PRODUÇÃO DE CÉLULAS ÍNTEGRAS DE Penicilium citrinum PARA APLICAÇÃO NA MODIFICAÇÃO DE ÓLEOS E GORDURAS
}

\author{
P. M. SATO ${ }^{1}$, D. R. VILELA ${ }^{1}$, K. C. de $\mathrm{CASTRO}^{1}$, A. B. ARCAS ${ }^{1}$, I. J. F. de ALMEIDA ${ }^{1}$; \\ L. H. RAMOS ${ }^{1}$ e G. S. S. ANDRADE ${ }^{1}$ \\ ${ }^{1}$ Universidade Federal de Alfenas, Instituto de Ciência e Tecnologia \\ E-mail para contato: grazielle.andrade@unifal-mg.edu.br
}

\begin{abstract}
RESUMO - O presente trabalho tem como objetivo produzir um biocatalisador a partir de células íntegras do fungo filamentoso $P$. citrinum com elevada atividade lipolítica, para ser aplicado em reações de modificação de óleos e gorduras. As células íntegras foram cultivadas por meio de fermentação submersa a $30^{\circ} \mathrm{C}$ por um período máximo de $120 \mathrm{~h}$. Após a separação do meio de cultivo, as células contendo lipase intracelular foram caracterizadas quanto as suas propriedades bioquímicas e cinéticas. As faixas de $\mathrm{pH}$ e temperatura ótimas obtidas foram de $7,5-8,0$ e $37-45^{\circ} \mathrm{C}$. O tempo de meia vida das células foram de 2,1 horas e a máxima velocidade de reação foi de $158,73 \mathrm{U} / \mathrm{g}$. A partir dos resultados obtidos, verificou-se a potencialidade das células íntegras de $P$. citrinum como biocatalisador de reações de transformação de óleos e gorduras.
\end{abstract}

\section{INTRODUÇÃO}

O uso de processos enzimáticos em substituição à catálise química tradicional desponta como uma alternativa adequada na obtenção de produtos de interesse não agressivos do ponto de vista ecológico. Entretanto, muitas aplicações industriais desses biocatalisadores são ainda limitadas pelo seu alto custo de produção e baixa produtividade, pois sendo em sua maioria enzimas extracelulares requer etapas posteriores de separação purificação e imobilização em suporte, por processos complexos para uso prático.

Como forma de reduzir estes custos, diversos estudos estão sendo direcionados na utilização de biocatalisadores a partir de células íntegras de fungos filamentosos com elevada atividade lipolítica, ou seja, alta produção de lipase intracelular, para mediar reações de hidrólise, esterificação e transesterificação de óleos vegetais (XIAO et al., 2010; ANDRADE et al., 2012; TALUKDER et al., 2013).

A literatura cita diversos artigos sobre a produção de lipase intracelular e a utilização de células íntegras livres ou imobilizadas obtidas a partir de diferentes espécies do gênero Rhizopus sp., Mucor sp. e Aspergillus sp., para aplicação em reações de transesterificação, sendo que a maior parte desses artigos reporta a utilização das células íntegras em processos de obtenção de biodiesel. No entanto ainda são escassos os trabalhos nacionais publicados sobre células integras do fungo filamentoso Penicillium citrinum com elevada atividade lipolítica para utilização em outras reações que envolvem a modificação de óleos e gorduras (ANDRADE et al., 2012). 
Nesse contexto, o presente trabalho propõe o desenvolvimento de um biocatalisador de baixo custo, oriundo do cultivo de células íntegras do fungo filamentoso $P$. citrinum com elevada atividade lipolítica, que possa ser utilizado de modo eficiente em reações de interesse para a indústria de óleos e gorduras.

\section{MATERIAIS E MÉTODOS}

\subsection{Materiais}

Micro-organismo: Todos os experimentos foram realizados empregando a linhagem do fungo filamentoso P. citrinum, gentilmente cedido pelo laboratório de Biocatálise da EELUSP.

Meio de cultura: $\mathrm{O}$ fungo foi cultivado em meio de cultura líquido composto por óleo de oliva (comercial) $30 \mathrm{~g} / \mathrm{L}$, peptona de soja (Acumedia) $70 \mathrm{~g} / \mathrm{L}, \mathrm{NaNO}_{3}$ (Synth) $1 \mathrm{~g} / \mathrm{L}, \mathrm{KH}_{2} \mathrm{PO}_{4}$ (Synth) $1 \mathrm{~g} / \mathrm{L}$ e $\mathrm{MgSO}_{4} \cdot 7 \mathrm{H}_{2} \mathrm{O}$ (Synth) $0,5 \mathrm{~g} / \mathrm{L}$.

\subsection{Metodologia Experimental}

Preparo das células íntegras: As células íntegras foram preparadas utilizando a técnica de fermentação submersa em frascos agitados, sendo empregada a metodologia descrita por Andrade et al. (2012), que serviu de base para a realização do cultivo. Em Erlenmeyers de $250 \mathrm{~mL}$ foram adicionados $100 \mathrm{~mL}$ de meio de cultivo, aos quais, após serem autoclavados $\left(121^{\circ} \mathrm{C} / 15 \mathrm{~min}\right.$ ), foram adicionados $3 \mathrm{~g}$ de azeite de oliva (comercial) assepticamente como agente indutor da produção de lipase. Para preparo do inóculo, os esporos foram raspados, suspensos em água estéril e submetidos à agitação até a obtenção de uma suspensão. Um volume de $200 \mu \mathrm{L}$ da suspensão foi inoculado em cada frasco agitado, os quais foram incubados por $96 \mathrm{~h}$ a $30^{\circ} \mathrm{C}$ sob agitação orbital em shaker (120 rpm).

Separação e recuperação das células íntegras: As células foram separadas do meio de cultura por filtração a vácuo, lavadas com água e secas em bomba de alto vácuo. A biomassa celular foi avaliada por meio de medida de peso seco e da atividade lipolítica.

Caracterização bioquímica e cinética das células íntegras: As células íntegras obtidas foram caracterizadas quanto as suas propriedades bioquímicas, através da determinação dos valores de $\mathrm{pH}$ e temperatura ótimos. A influência da concentração de substrato foi avaliada através da variação da concentração de substrato $(100$ a $1000 \mu \mathrm{M})$, neste caso o azeite de oliva. Os parâmetros cinéticos: constante cinética de Michaelis-Menten $\left(\mathrm{k}_{\mathrm{m}}\right)$ e velocidade máxima de reação $\left(\mathrm{V}_{\text {máx }}\right)$ foram determinados através do ajuste da equação de MichaelisMenten pela linearização de Lineaweaver-Burk. A estabilidade térmica foi avaliada através da incubação dos das células ao longo de um determinado tempo (120 minutos) em diferentes temperaturas $\left(37 \mathrm{a} 60^{\circ} \mathrm{C}\right)$. Em intervalos de $30 \mathrm{~min}$, foram retiradas as amostras as quais foram imediatamente resfriadas em banho de gelo para interromper a reação de inativação. A atividade residual foi avaliada, a fim de se determinar a constante de inativação térmica $\left(\mathrm{k}_{\mathrm{d}}\right)$ e tempo de meia vida $\left(\mathrm{t}_{1 / 2}\right)$. Todos os métodos de avaliação foram realizados através da dosagem da atividade lipolítica. 


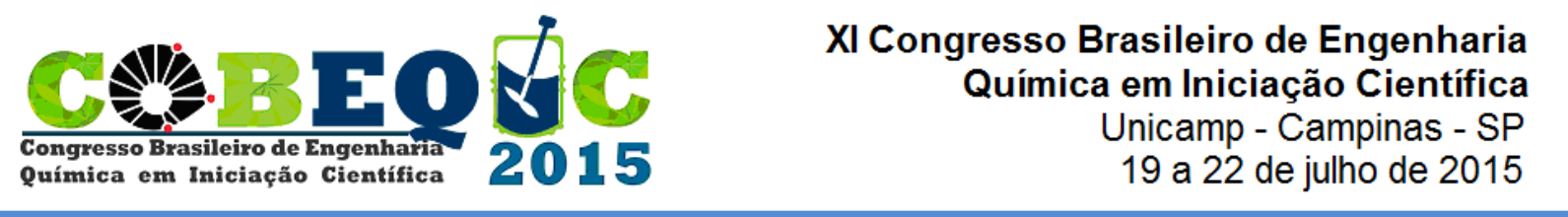

\subsection{Metodologia Analítica}

Determinação da atividade lipolítica: A atividade enzimática das células imobilizadas foi determinada pelo método de hidrólise, conforme metodologia modificada por Soares et al. (1999). Uma unidade de atividade foi definida como a quantidade de enzima que libera $1 \mu \mathrm{mol}$ de ácido graxo por minuto de reação, nas condições do ensaio. As atividades foram expressas em $\mu$ moles/g.min (U/g).

Determinação do teor de umidade: A umidade das células imobilizadas foi determinada pela diferença entre a massa úmida e a massa seca após secagem em estufa por $24 \mathrm{~h}$ a $100^{\circ} \mathrm{C}$.

\section{RESULTADOS E DISCUSSÃO}

\subsection{Preparação das células íntegras}

A fim de verificar o perfil de crescimento do fungo $P$. citrinum em fermentação submersa, foram realizados cultivos preliminares em frascos erlenmeyers contendo $100 \mathrm{~mL}$ do meio de cultura. Após 24 e $48 \mathrm{~h}$ de incubação, verificou-se que não houve crescimento do micro-organismo. No entanto, decorridos 72,96 e 120h, foi observado o crescimento do fungo na forma de pellets, os quais foram analisados quanto à massa seca de micélio e à atividade lipolítica do micélio e do filtrado (Figura 1a-b).

Figura 1 - Perfil de crescimento celular (a) e das atividades intra e extracelular (b) ao longo do tempo de incubação.

(a)

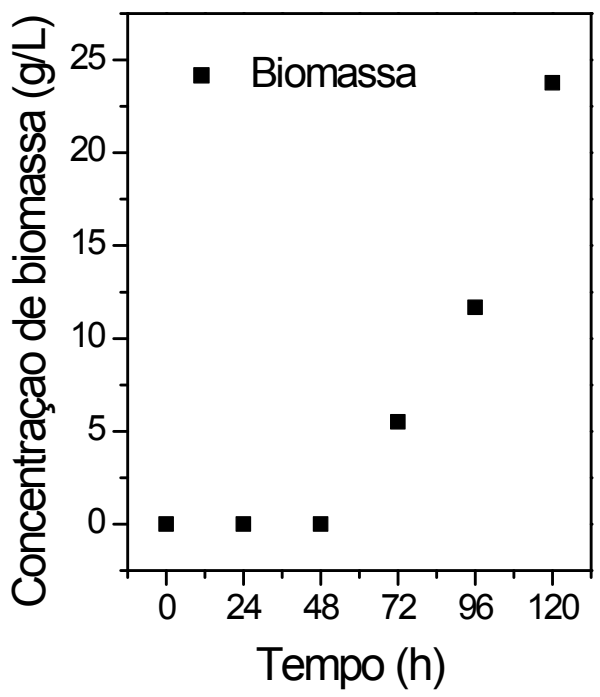

(b)

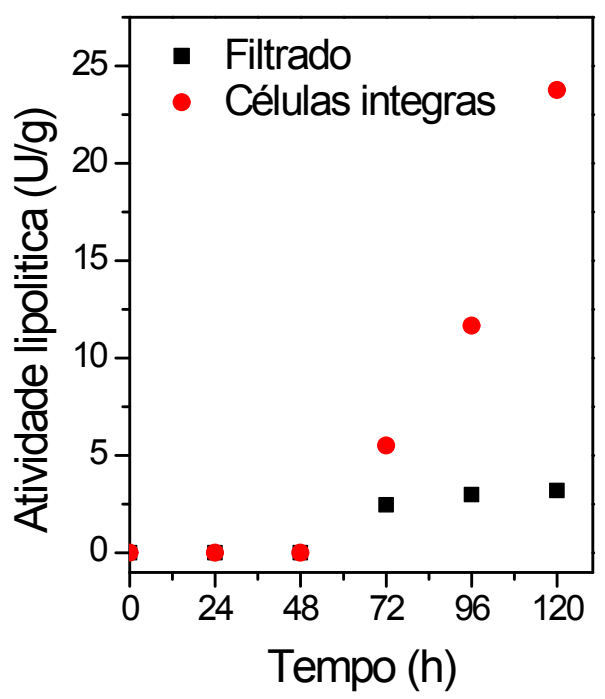

Verifica-se na Figura 1(a) que após 48h de cultivo, o perfil de crescimento celular é semelhante a um perfil padrão de crescimento microbiano e a massa obtida aumenta conforme se aumenta o tempo de incubação, obtendo-se o maior valor $(23,2 \mathrm{~g} / \mathrm{L})$ em $120 \mathrm{~h}$. 
Independente do tempo de cultivo, elevados valores de atividade enzimática no micélio (atividade intracelular) foram obtidos em comparação aos valores de atividade enzimática no filtrado (atividade extracelular) (Figura 1b), indicando que a maior parte da lipase produzida ficou aderida ao micélio. $\mathrm{O}$ maior valor de atividade intracelular obtido foi de $23,8 \mathrm{U} / \mathrm{g}$ com tempo de cultivo de $120 \mathrm{~h}$.

\subsection{Caracterização das células íntegras}

$\mathrm{O}$ pH ótimo de atuação das células íntegras de $P$. citrinum na hidrólise do azeite de oliva foi avaliado atráves da dosagem da atividade lipolítica à $37^{\circ} \mathrm{C}$ sob diferentes valores de pH: 6,$0 ; 6,5 ; 7,0$ e 8,0 e a temperatura ótima foi avaliada através da dosagem da atividade lipolítica em pH 7,0 sob diferentes valores de temperatura de incubação: $30,37,45$ e $50^{\circ} \mathrm{C}$. Os resultados obtidos estão ilustrados na Figura 2(a-b).

Figura 2 - Influência do pH (a) e da temperatura (b) na atividade lipolítica das células de $P$. citrinum.

(a)

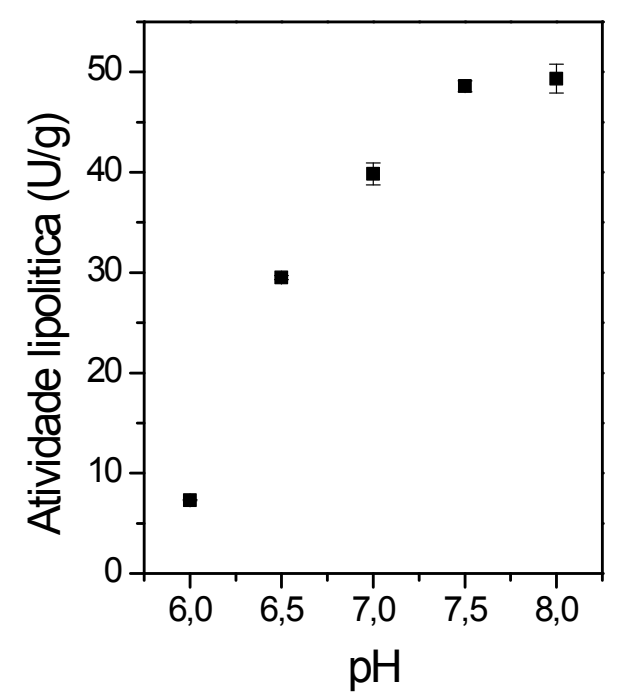

(b)

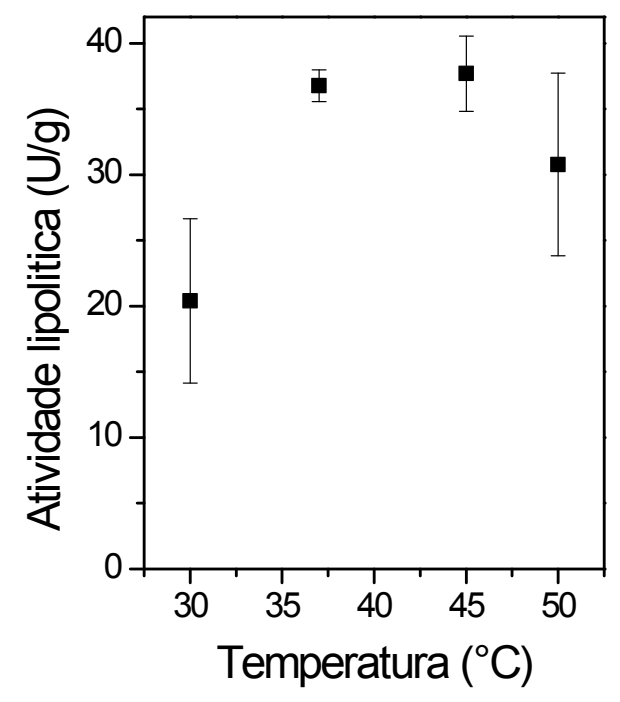

A Figura 2a mostra que a melhor faixa de atuação das células ficou entre os pHs 7,5 e 8,0 com valores máximos de 48,58 e 49,33 U/g, respectivamente. Essa faixa de pH encontrase dentro dos padrões encontrados para a maioria das lipases extracelulares imobilizadas. $\mathrm{Na}$ Figura $2 \mathrm{~b}$ encontra-se maior atividade das células na faixa de temperatura de $37 \mathrm{a} 45^{\circ} \mathrm{C}$ com valores de 36,78 e $37,70 \mathrm{U} / \mathrm{g}$, respectivamente. Isso sugere que a célula íntegra age como um suporte e oferece proteção a lipase intracelular, aumentado sua estabilidade a elevados valores de $\mathrm{pH}$ e temperaturas.

A estabilidade térmica foi testada por meio da determinação das atividades lipolíticas residuais após a incubação numa temperatura de $60^{\circ} \mathrm{C}$ em meio aquoso (tampão fosfato de sódio $0,1 \mathrm{M}$ ) em $\mathrm{pH} 7,0$. A atividade residual foi determinada a $37^{\circ} \mathrm{C}$ por $5 \mathrm{~min}$, de acordo 
com a metodologia descrita por Soares et al. (1999). Observa-se na Figura 3 a atividade residual das células íntegras de $P$. citrinum, após o tratamento térmico em diferentes tempos.

Figura 3 - Estabilidade térmica das células de P. citrinum em diferentes tempos de incubação a $60^{\circ} \mathrm{C}$.

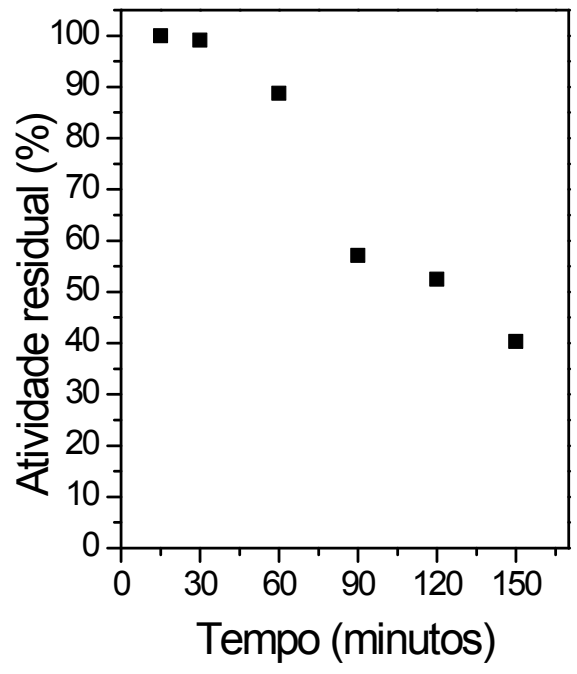

A partir desses resultados, calculou-se a constante de inativação térmica $\left(\mathrm{k}_{\mathrm{d}}\right)$ e o tempo de meia-vida $\left(\mathrm{t}_{1 / 2}\right)$. O tempo de meia-vida é definido como o tempo necessário para que ocorra uma redução de $50 \%$ da atividade inicial da enzima. A constante de inativação $\left(\mathrm{k}_{\mathrm{d}}\right)$ foi calculada pela equação 3 e o tempo de meia-vida pela equação 4 . O valor de $k_{d}$ obtido para as células livres foi de $0,33 \mathrm{~h}^{-1}$ e o $\mathrm{t}_{1 / 2}$ foi igual a $2,1 \mathrm{~h}$.

$$
\begin{aligned}
& A=A_{0} \exp \left(-K_{d} \cdot t\right) \\
& t_{1 / 2}=\ln 0,5 /-k_{d}
\end{aligned}
$$

Para verificar o efeito da concentração do substrato sobre a atividade lipolítica e a ocorrência de possível inibição da lipase intracelular, a porcentagem do azeite de oliva na emulsão foi variada na faixa de $5 \%$ a $70 \%$ e os parâmetros cinéticos $\mathrm{k}_{\mathrm{m}}$ e $\mathrm{V}_{\text {máx }}$ foram determinados através do ajuste da equação de Michaelis-Menten e linearização de Lineaweaver-Burk. Os ensaios foram conduzidos sob as condições ótimas determinadas, e os resultados obtidos são mostrados na Figura 4.

Verifica-se que os maiores valores de atividade enzimática 161,74 e 164,7 U/g foram obtidos utilizando concentrações de 50 e $60 \%$ de azeite de oliva, que correspondem a 1860 e $2232 \mathrm{mM}$ de ácidos graxos, respectivamente. A partir disso há uma tendência na dimunição da atividade, o que indica que a lipase começa a sofrer efeitos inibitórios pela alta concentração de substrato. Assim, tem-se a velocidade máxima de reação no valor de 158,7 $\mathrm{U} / \mathrm{g}$ e a constante $\mathrm{K}_{\mathrm{m}}$ em $263 \mathrm{mM}$. 
Figura 4 - Atividade das células de $P$. citrinum em função da concentração de substrato (expresso em total de ácidos graxos contido na emulsão de azeite de oliva e água).

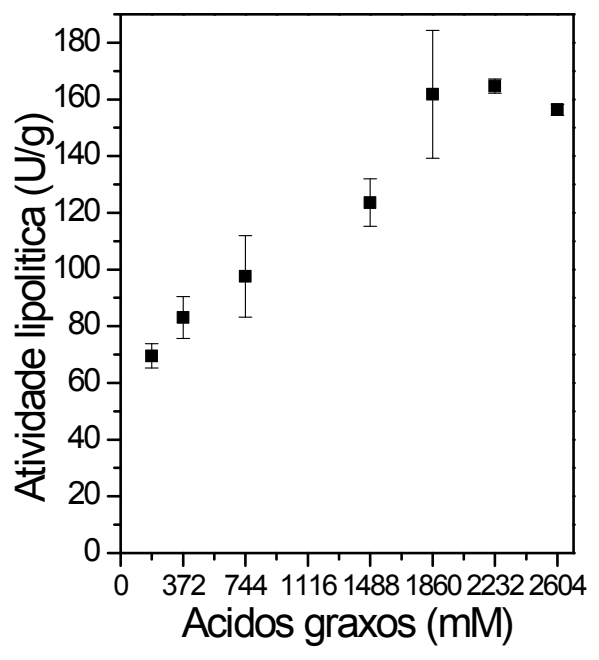

\section{CONCLUSÕES}

Os resultados obtidos são promissores e sugerem a potencialidade na aplicação de células íntegras de $P$. citrinum para mediar reações de modificação e óleos e gorduras. No entanto estudos adicionais tais como otimização do meio de cultivo e imobilização celular ainda se fazem necessários a fim de promover o aumento da produção de lipase intracelular pelas células.

\section{AGRADECIMENTOS}

Os autores agradecem a FAPEMIG pelo suporte financeiro.

\section{REFERÊNCIAS}

ANDRADE, G. S. S.; FREITAS, L.; OLIVEIRA, P. C.; DE CASTRO, H. F. Screening, immobilization and utilization of whole cell biocatalysts to mediate the ethanolysis of babassu oil. J. Mol. Catal. B: Enzym., v. 84, p. 183-188, 2012.

SOARES, C. M. F.; CASTRO, H. F.; MORAES, F. F.; ZANIN, G. M. Characterization and utilization of Candida rugosa lipase immobilized on controlled pore silica. Appl. Biochem. Biotechnol., v.77/79, p. 745-757, 1999.

TALUKDER, MD.M.R.; LEE, H.Z.S.; LOW, R.F.; PEI-LYN, L.C.; WARZECHA, D.; WU, J. Potential use of whole cell lipase from a newly isolated Aspergillus nomius for methanolysis of palm oil to biodiesel. J. Mol. Catal. B. Enzym., v. 89, p. 108-113, 2013.

XIAO, M.; MATHEW, S.; OBBARD, P. A newly isolated fungal strain used as whole cell biocatalyst for biodiesel production from palm oil. Global Change Biol. Bioeng., v. 2, p. 45-51, 2010. 